\title{
Reports indicate Government ready to extend HPV vaccination to boys
}

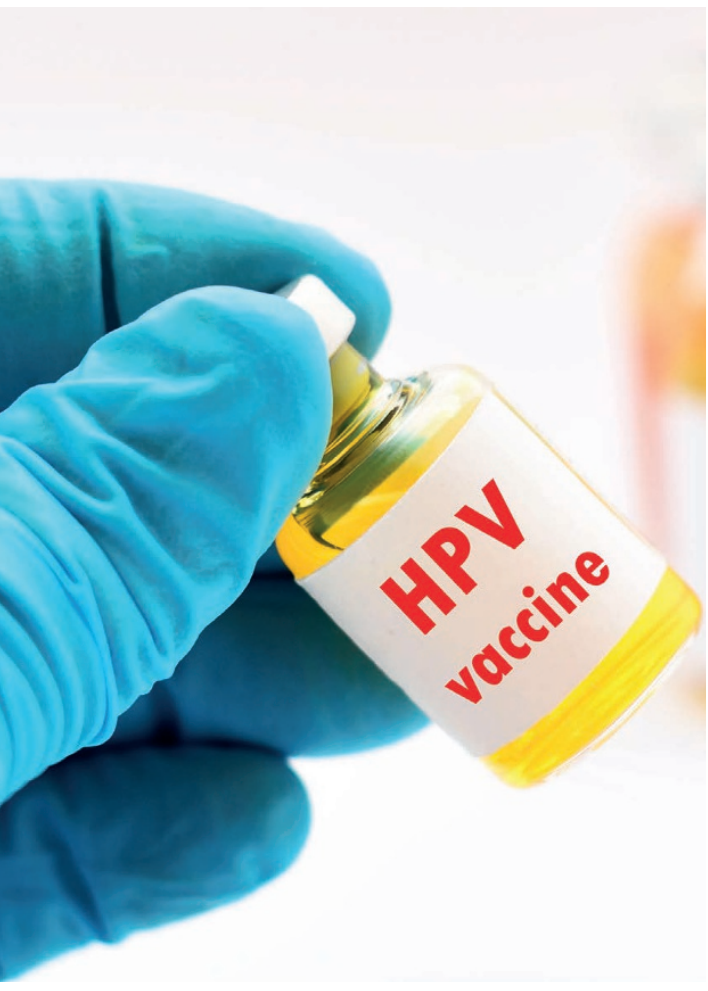

The British Dental Association has welcomed reports that the Government is preparing to commit to funding HPV vaccinations for boys.

The BDA has been a leading voice in the call for a gender neutral approach to the vaccinations, which are currently provided to school age girls as protection from cervical cancer. HPV has emerged as the leading cause of oral cancer, especially among young people, and rates are rising steeply overall. It is linked to $5 \%$ of all cancers worldwide, including some that affect only men.

Over the last decade, oral cancer incidence rates have increased by almost a quarter (23\%) in the UK, making it one of the fastest rising types of cancer in the country, and it is increasing more rapidly among men than among women.

The Joint Committee on Vaccination and Immunisation (JCVI) had delayed offering concrete recommendations to ministers on a universal programme. They have received widespread criticism for questioning the cost effectiveness of vaccinating boys, based on unpublished, flawed and out of date modelling.

The BDA and members of the HPV Action coalition are urgently seeking clarification on when the jabs will be offered. Peter Baker, Campaign Director of HPV Action, said 'The JCVI has been considering whether boys should receive the HPV vaccination for five long years and, despite repeated promises of a decision, has not yet made one. It has also refused to look at the equality or ethical issues or take account in its modelling of the full economic cost of the diseases caused by HPV. However, we very much hope that recent press reports are accurate and that the government is on the verge of making the right decision. If the current girls-only vaccination programme continues, around 400,000 more boys each year will be left unprotected and at risk of oral, anal and penile cancers as well as genital warts.

\section{Tooth fairy payments continue to rise}

British children receive almost $£ 24$ million each year from the Tooth Fairy, according to the results of a new nationwide survey. The poll, conducted by the Oral Health Foundation, found that the nation's youngsters are receiving an average of $£ 1.58$ per tooth. The charity surveyed more than 2,000 parents, from across the United Kingdom, to find out how much the Tooth Fairy leaves for a child's baby teeth when they fall out. With roughly 15 million baby teeth falling out each year, it is estimated that the Tooth Fairy is shelling out $£ 23.7$ million annually, a whopping $43.6 \%$ more since 2011 (£16.5 million).

Chief Executive of the Oral Health Foundation, Dr Nigel Carter OBE, says: ‘The Tooth Fairy business is increasingly lucrative and has seen major inflation in recent years, but it is really important that children are mindful of just how precious the baby teeth they are placing under their pillows are.

'Many believe that milk teeth don't need to be healthy, as they will just fall out anyway, but this could not be further from the truth.
'The health of children's baby teeth and their oral health in adulthood are closely linked so it is vital that a child's mouth is kept clean and healthy. We want to see children's milk teeth fall out naturally and healthily, free from signs of decay.'

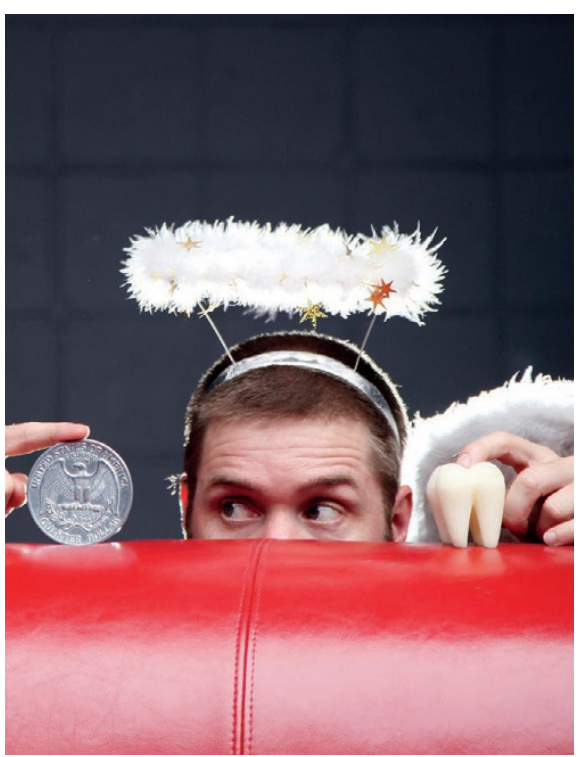

Chief Dental Officer for Scotland to step down from role

BDA Scotland has responded to news that Chief Dental Officer Margie Taylor is stepping down from the role in November.

Chair of the BDA's Scottish Council Robert Donald said: 'We would like to thank Margie Taylor for her hard work over the past 11 years. The BDA commends Margie on the way she has engaged with the Association during her tenure. This profession recognises her achievements during this time, including the introduction of the Childsmile programme, and her role in resolving decontamination issues.

'The BDA looks forward to working constructively with Margie and her team in the coming months to help improve oral health in Scotland, and to ensure dentists have a central role in implementing the Oral Health Improvement Plan.' 